\title{
Existe convergência de patenteamento no Brasil?*
}

\author{
Priscila Medeiros de Oliveira** \\ Eduardo Gonçalves ${ }^{* * *}$ \\ Eduardo Almeida****
}

Recebido: 04/11/2015 Versão revisada (entregue): 08/03/2016 Aprovado: 31/03/2016

\section{RESUMO}

Este trabalho investiga a existência de convergência de patenteamento entre as microrregiões brasileiras. Para confirmar tal hipótese, foi estimado um painel espacial para dados de patentes referentes ao período 2000-2011, controlando-se fatores internos e externos que afetam a taxa de crescimento do patenteamento per capita. Além de microrregiōes, também foram utilizadas mesorregiôes e áreas de influência de cidades (Regic) para verificar a robustez dos resultados, ao mesmo tempo que se testa o problema da unidade de área modificável (Modifiable Areal Unit Problem - Maup). Dois resultados principais são constatados: existe um processo de convergência ou catching up tecnológico entre as microrregiôes brasileiras; e a dependência espacial é sensível às diferentes escalas geográficas quando se estuda o crescimento do patenteamento per capita no Brasil

Palavras-Chave | Convergência de Patenteamento; Painel de Dados Espacial; Patentes; Problema da Unidade de Área Modificável.

Códigos-JEL | R11; O31; O33

\footnotetext{
* Os autores agradecem o apoio financeiro do CNPq, FAPEMIG e UFJF e a equipe do Instituto Nacional de Propriedade Industrial, responsável pela base de dados.

** Universidade Federal de Juiz de Fora (UFJF), Juiz de Fora (MG), Brasil. E-mail: priscilam_jf@hotmail.com

*** Universidade Federal de Juiz de Fora (UFJF), Juiz de Fora (MG), Brasil. E-mail: eduardo.goncalves@uff.edu.br

****Universidade Federal de Juiz de Fora (UFJF), Juiz de Fora (MG), Brasil. E-mail: eduardo.almeida@ufff.edu.br
} 


\section{Is there a convergence of patenting in Brazil?}

\section{ABSTRACT}

The article aims to analyze the existence of patenting convergence among Brazilian microregions. In order to confirm this hypothesis, a spatial panel model is estimated for patent data from 2000 to 2011, taking into account the control of internal and external regional factors that affect the growth rates of per capita patenting. In addition to micro-regions, mesoregions and the Areas of Influence of Cities Project (REGIC), the paper tests the robustness of estimations in order to check the Modifiable Areal Unit Problem (MAUP). Two main findings emerge: there is a convergence process or technological catch-up among Brazilian micro-regions; and spatial dependence is sensitive to different geographical scales when we study the growth of per capita patenting in Brazil.

KeYWords: Patenting Convergence; Spatial Panel Data; Patents; Modifiable Areal Unit Problem

JEL-CODES: R11; O31; O33. 


\section{Introdução}

Os artigos de Solow (1956), Lucas (1988) e Romer (1990) popularizaram o debate sobre o processo de convergência de renda, ou seja, se regiōes mais pobres tendem a crescer mais rápido do que regióes mais desenvolvidas. Como determinante de longo prazo do nível de renda per capita, as diferenças de capacidade tecnológica assumem importância fundamental neste debate. Fagerberg (1994) argumenta que esforços para reduzir diferenças tecnológicas é um fator que explica significativamente o crescimento econômico de países industrializados. Tendo em vista as relações entre tecnologia e crescimento, é possível que a discussão de convergência de atividade tecnológica deva anteceder a de convergência de renda.

Para gerar tecnologia, uma região deve ter escala urbana mínima (FELDMAN; FLORIDA, 1994). Existem características inerentes às cidades, como concentração de profissionais qualificados, serviços produtivos especializados, facilidade de troca de informaçôes e conhecimento entre os agentes, entre outras, que tornam a aglomeração espacial de atividade tecnológica um resultado previsível.

O’Huallacháin e Leslie (2005) relacionam concentração da inovação com crescimento econômico regional e medem a convergência tecnológica pelo patenteamento per capita em estados norte-americanos (1963-2003). Os autores encontram o resultado de convergência tecnológica até 1993. No período 1993-2003, constatou-se divergência tecnológica, com a expansão do patenteamento sendo concentrada em alguns estados.

No caso brasileiro, existem muitos trabalhos que tratam a localização da atividade produtiva (DINIZ, 1993; AZZONI, 1990; LEMOS et al., 2005). Estes trabalhos apontam para perda relativa da participação da área metropolitana de São Paulo no produto industrial brasileiro. Segundo Lemos et al. (2005), este processo de desconcentração é resultado de prejuízos advindos do tamanho excessivo da região, juntamente com ascensão de outros centros urbanos do país localizados ainda no eixo Sul-Sudeste. Em termos de atividade tecnológica, Freitas et al. (2010) constataram a existência de convergência tecnológica para o período de 1990 a 2001 no Brasil, empregando estados da federação como unidade espacial de análise.

Os estudos mencionados acima que trabalham com a convergência tecnológica utilizam estados como unidade geográfica. No entanto, Arbia (2006) argumenta que o resultado de qualquer análise de regressão baseada em dados espaciais depende, essencialmente, do nível de agregação geográfica escolhida e não pode simplesmente ser transferido de um nível de agregação para outro. Anselin (1988) aborda o pro- 
blema da unidade de área modificável (Modifiable Areal Unit Problem - Maup), pelo qual diferentes níveis de agregação e a organização espacial, em zonas, afetam a magnitude de várias medidas associadas às unidades, os coeficientes de autocorrelação espacial e os parâmetros do modelo de regressão.

A questão a ser respondida neste artigo é se existe ou não convergência de patenteamento entre as regiôes brasileiras. Esse tipo de convergência, chamada também às vezes de catching-up, será avaliada por meio de registros de patente, compilados pelo Instituto Nacional de Propriedade Industrial (Inpi). Para testar a sensibilidade dos resultados de convergência do patenteamento ao problema de escala, pretende-se utilizar diferentes unidades espaciais, tais como microrregiōes geográficas, mesorregiōes e Regiôes de Influência das Cidades (Regic), ${ }^{1}$ do Instituto Brasileiro de Geografia e Estatística (IBGE, 2013). Essa abordagem é proposta com o objetivo de se testar a robustez dos resultados, quando se usam diferentes recortes regionais, além de verificar se ocorre o problema de escala no processo de convergência da atividade inventiva, assim como foi feita por Resende et al. (2016) para convergência de renda.

Em termos econométricos, adota-se a equação de convergência com um painel de dados espaciais, a fim de tratar a dependência espacial. A especificação econométrica segue contribuições dos modelos de crescimento e convergência de renda, como em Solow (1956), Barro e Sala-i-Martin (1992) e Sala-i-Martin (1996), considerando também fatores internos e externos à região que podem contribuir para o desempenho inventivo e, consequentemente, para explicação da taxa de convergência de patenteamento no Brasil. Como fatores internos, o presente trabalho considera características estruturais da região, a saber: estoque de capital humano; presença trabalhadores em ocupações técnico-científicas; tamanho dos estabelecimentos; densidade dos trabalhadores; e nível de PIB per capita. Como fatores externos, são considerados a tecnologia comprada do exterior, a partir da importação de bens de capital, e os transbordamentos representados pela defasagem espacial da variável dependente.

O presente trabalho está estruturado em quatro seções, além desta introdução. A seguir, é feita a revisão de literatura. Posteriormente aborda-se a metodologia implementada para o presente estudo e são descritos os dados utilizados. Os resultados são expostos e discutidos e, finalmente, apresentam-se as conclusões do estudo.

1 A Regic foi concebida a partir de uma visão que combina o processo de urbanização e o processo de integração do mercado nacional, com o surgimento de estruturas verticais que estabelecem relaçôes em rede e interconexốes da gestão, da infraestrutura e das atividades produtivas (IBGE, 2013). 


\section{Revisão da literatura}

A análise da convergência atrai a atenção de muitos estudiosos, existindo um grande número de trabalhos que discutem essa questão na literatura sobre crescimento econômico, em que foi aplicada pioneiramente. A análise de convergência- $\beta$ de renda é uma consequência da solução do modelo de crescimento neoclássico de Solow (1956), que usa uma função de produção com retornos constantes de escala, para mostrar que a economia tende para um estado estacionário e que o crescimento de longo prazo é determinado pelo comportamento da mudança tecnológica, que é exógena. Em virtude da produtividade marginal decrescente do capital, regiōes com baixo nível de estoque de capital possuem altas taxas de retornos do mesmo e, por isso, devem crescer mais rápido do que as regiōes ricas, nas quais o estoque de capital é superior. Assim, uma relação negativa entre o nível de renda inicial e a subsequente taxa de crescimento tem sido interpretada como o melhor critério para julgar a existência ou não de convergência de renda. Portanto, essa é a relação causal de interesse nessa análise.

Foi assim a análise efetuada por Baumol (1986), para 16 países industrializados, ao longo dos anos de 1870 a 1979 . Porém, o autor usou a taxa anual de crescimento da produtividade do trabalho no período estudado como variável dependente e o logaritmo da produtividade do trabalho no período inicial como variável independente.

Por sua vez, De Long (1988) demonstrou que os resultados de Baumol eram espúrios devido a dois graves problemas: a seleção ex-post da amostra e erros de medida na variável independente. A despeito dessas fontes de má especificação, duas correntes teóricas surgiram. Na primeira, autores como Barro e Sala-i-Martin (1992) e Mankiw et al. (1992) buscaram estender o modelo neoclássico de crescimento, de modo a reconciliá-lo com a evidência empírica. A heterogeneidade das condiçôes iniciais na regressão deveria, então, ser considerada. Dessa forma, a análise de convergência precisava ser condicionada para se estimar o parâmetro de convergência. Para se fazer isso econometricamente, era preciso inserir na regressão de convergência variáveis de controle, representando essas condições iniciais diferentes para cada região. Mankiw et al. (1992) desenvolveram o modelo de Solow aumentado com capital humano, ou seja, inserindo essa variável de controle adicional para condicionar a equação de convergência.

Uma segunda corrente propõe modelos de crescimento endógeno, em que o capital apresenta retornos constantes ou crescentes e, portanto, nenhuma tendência 
à convergência de renda per capita se manifesta. Foi a partir dessa segunda corrente que se iniciou o estudo sobre o progresso tecnológico e sua real importância para o crescimento dos países. Lucas (1988) e Romer (1990) apontam que a inovação está entre as causas "profundas" do progresso econômico das nações. A teoria do crescimento endógeno indica que o conhecimento está sujeito a retornos crescentes por causa das externalidades inerentes à sua produção e à sua utilização.

Os gastos com P\&D, insumo da inovação nestes modelos, são uma das causas do progresso econômico das nações, pois, em razão das propriedades do conhecimento técnico, rival e parcialmente excludente, sua produção e uso geram retornos crescentes. Estas características possuem influência direta sobre o tema de convergência de renda, dado que os retornos crescentes, fruto do progresso técnico, permitiriam crescimento sustentado e, portanto, divergência da renda entre os países.

Assim, a partir desses modelos, a acumulação de conhecimento e os seus transbordamentos se tornaram a base da teoria do crescimento endógeno na economia. As principais linhas de trabalhos empíricos que investigam os transbordamentos de conhecimento e os determinantes regionais da inovação, segundo Feldman (1999), são: aqueles que rastreiam os transbordamentos por meio de citaçóes de patentes; os que medem a mobilidade de mão de obra qualificada, partindo da noção de que o conhecimento está incorporado nos indivíduos; os que consideram o papel da difusão de conhecimento em bens comercializados entre naçōes ou regiōes; e os que empregam a função de produção de conhecimento para explicar a determinação do produto da inovação. Tendo em vista a importância da inovação para o crescimento econômico, ganham relevância também as razões para a concentração da inovação no espaço. Krugman (1991) afirma que a aglomeração ou concentração geográfica do conhecimento deve ser uma fonte de retornos crescentes. Por esta razão, a localização pode aumentar a geração de inovação e produzir maiores taxas de avanço tecnológico e do crescimento econômico (FELDMAN, 1999).

Se, por um lado, os argumentos acima enfatizam o resultado de concentração e divergência tecnológica regional, por outro, segundo Abramovitz (1986), o esforço de regiões relativamente atrasadas para alcançarem as "líderes" em relação às suas tecnologias e, portanto, produtividade poderia fazer com que o crescimento dessas "seguidoras" fosse inclusive maior do que o da própria "líder". Desse modo, o fenômeno definido por esse autor como catching up seria uma forma de diminuir a concentração das atividades inventivas e, em consequência, das atividades produtivas e tecnológicas, possibilitando convergência tecnológica. 
Assim, em uma primeira fase, regióes emergentes deveriam criar possibilidade de imitação de tecnologias já existentes, precisando, para tanto, possuir condições mínimas de capacitação social, que envolvem desenvolvimento de infraestrutura educacional adequada, bem como implementação de órgãos institucionais de pesquisa e cooperação, além de garantir condiçōes macroeconômicas e monetárias estáveis e confiáveis. Em uma segunda fase, é necessário que a região seja capaz de aperfeiçoar as tecnologias existentes para então completar com sucesso a implantação do processo de catching up (ABRAMOVITZ, 1986).

Em relação a variáveis indicadoras de atividade tecnológica, Gonçalves (2007) constatou que patentes per capita possuem um padrão de associação espacial global positivo, evidenciando de forma clara um regime de polarização Norte-Sul na distribuição da atividade tecnológica brasileira. Em termos de determinantes espaciais, Gonçalves e Almeida (2009), Montenegro, Gonçalves e Almeida (2011) e Araújo (2013) investigaram as características tecnológicas, industriais, urbanas e institucionais. Montenegro, Gonçalves e Almeida (2011) estudaram especificamente as microrregióes de São Paulo. Gonçalves e Almeida (2009) analisaram os determinantes da inovação a nível nacional usando as 558 microrregiōes brasileiras. Araújo (2013) também usou microrregiōes geográficas, mas suas estimaçōes foram feitas por meio de um Tobit espacial, que controla para a característica de que muitas microrregiôes não possuem patentes. Questões relativas às disparidades estaduais de atividade tecnológica foram estudadas por Freitas et al. (2010), que verificaram a existência de concentração macrorregional da atividade tecnológica nos estados do Sul e Sudeste, ainda que houvesse indícios de convergência da taxa de crescimento das patentes per capita no período 1990-2001.

O presente artigo contribui para esse debate ao propor uma análise de convergência de patenteamento, buscando identificar se as regiōes com menor capacidade inventiva possuem crescimento mais rápido do que aquelas "líderes", como São Paulo, o que contribuiria para um processo de desconcentração econômica no longo prazo.

\section{Metodologia}

\subsection{Estratégia empírica}

O modelo proposto por Solow (1956) prevê convergência dos níveis de renda per capita dos países até o estado estacionário. Por sua vez, Barro e Sala-i-Martin (1992) e Sala-i-Martin (1996) propõem duas formas distintas de convergência inter-regional, 
a $\beta$-convergência e a $\sigma$-convergência. Neste artigo, pretende-se analisar a primeira, tomando como variável dependente o crescimento das patentes per capita, sendo explicada pelas patentes per capita no período inicial da análise. Do exposto:

$$
\ln \left(P A T p c_{i, t} / P A T p c_{i, t-1}\right)=\alpha+\beta \ln \left(P A T p c_{i, t-1}\right)+\varepsilon_{i, t}
$$

Entretanto, a literatura empírica encontra evidência favorável não à convergência absoluta, mas sim à convergência condicional, ou seja, regiōes com determinadas características específicas semelhantes tenderiam a convergir para um mesmo estado estacionário tecnológico. Dessa forma, no modelo proposto nesse estudo, variáveis explicativas adicionais foram incluídas na regressão para que houvesse um controle de fatores específicos de cada região:

$I F_{i, t}=\left\{C H_{i, t}, P D p_{i, t}, E S T_{i, t}, D E N S_{i, t}, P I B p c_{i, t}, T A M_{i, t}\right\}$,

onde $I F_{i, t}$ é um vetor de fatores internos, ou seja, um vetor de variáveis de controle que refletem características da região $i$. No estudo em questão, esse vetor é composto pelas seguintes variáveis: $C H_{i, t}:$ capital humano; $P D p_{i, t}:-$ capacidade de P\&D privado; $E S T_{i, t}:$-número de estabelecimentos com mais de um funcionário per capita na região; $D E N S_{i, t^{*}}$ - densidade de emprego; PIBpc $c_{i, t}$ - Produto Interno Bruto per capita da região; $T A M_{i, t}$ - porcentagem de grandes empresas na região.

Por fim, Usai (2011) afirma que a literatura teórica e empírica sugere que a produção de conhecimento em uma região pode depender não apenas de seus próprios esforços de investigação, mas também do estoque de conhecimento disponível em toda a economia e da sua capacidade de explorá-la. Dessa forma, fatores externos, como fluxos de comércio, investimento externo direto, importações de máquinas e equipamentos, mercado comum de mão de obra qualificada e transbordamentos de conhecimento podem afetar o crescimento da atividade inventiva das regiōes. Os transbordamentos envolvem ações de um agente econômico que, ao criar inovação, geram externalidades para outros agentes, que podem ser empresas do mesmo setor, setores diferentes ou empresas de fora da região (GRILICHES, 1992).

Desse modo, para investigar se tais fatores externos também impactam o crescimento da atividade tecnológica de uma região, é inserido o vetor, que inclui parcela do PIB regional gasta com importação de bens de capital, oriunda dos principais parceiros comerciais do Brasil (variável ), e a defasagem espacial da variável dependente, no sentido de capturar a influência do crescimento do conhecimento externo à região (transbordamentos de conhecimento). 
Do exposto, o vetor de fatores externos $\left(E F_{i t}\right)$ é representado como:

$E F_{i, t}=\left\{B K_{i, t-1}, W\left(P A T p c_{i, t} / P A T p c_{i, t-1-1}\right)\right\}$

Dessa maneira, a equação de convergência condicional a ser estimada é a seguinte:

$$
\begin{aligned}
& \ln \left(P A T p c_{i, t} / P A T p c_{i, t-1}\right)=\alpha+\beta \ln \left(P A T p c_{i, t-1}\right)+\delta_{1} \ln \left(C H p c_{i, t}\right)+\delta_{2} \ln \left(S A L_{i, t}\right)+\delta_{3} \ln \left(E S T p c_{i, t}\right)+ \\
& \delta_{4} \ln \left(U R B p c_{i, t}\right)+\delta_{5} \ln \left(P I B p c_{i, t}\right)+\delta_{6} \ln \left(T A M p c_{i, t}\right)+\gamma_{7} \ln \left(B K_{i, t},+\rho W \ln \left(P A T p c_{i, t} / P A T p c_{i, t-1}\right)\right.
\end{aligned}
$$

onde $\alpha$ é a constante e $\beta$ corresponde ao coeficiente do nível de patente per capita inicial, que deve indicar se existe um processo de convergência ou divergência de atividade inventiva, dependendo do sinal e significância deste coeficiente. Por sua vez, $\delta$ representa os coeficientes do vetor de características internas, enquanto $\gamma, \rho$ são os coeficientes do vetor de características externas, que representam, respectivamente, o coeficiente da parcela do PIB gasto com importação e a defasagem espacial da variável dependente.

Definida a equação principal, deve-se acrescentar que a estratégia empírica deste trabalho consiste em selecionar, por intermédio do teste de Hausman, o modelo de dados em painel apropriado, ou efeito fixo ou efeito aleatório. Em seguida, pelo teste CD de Pesaran (2007), ${ }^{2}$ procura-se verificar a presença de dependência espacial nos dados longitudinais.

Confirmada a existência de dependência espacial, torna-se necessário captar tais efeitos. Uma das maneiras para se fazer isso é construir um modelo econométrico-espacial, incluindo defasagens espaciais. Levando em conta que a defasagem espacial da variável dependente é parte fundamental na teoria exposta por representar os transbordamentos de conhecimento externos à região (VARGA, 1998; MORENO; PACI; USAI, 2005), a especificação da equação (4) é utilizada para definir o modelo a ser testado no estudo. Este é chamado de modelo de defasagem espacial ou SAR, que pode ser representado como se segue:

$y_{\mathrm{it}}=\rho W_{\mathrm{ij}} y_{\mathrm{ij}}+X_{\mathrm{it}} \beta+\varepsilon_{i}$

Reparametrizando a equação (5), tem-se:

$y_{\mathrm{it}}=\left(X_{\mathrm{it}} \beta+\varepsilon_{i}\right)\left(I n-\rho W_{\mathrm{ij}}\right)^{-1}$

2 A rejeição da hipótese nula do teste $\mathrm{CD}$ de Pesaran indica dependência espacial. 
Desse modo, é possível separar os impactos marginais diretos e indiretos. Os impactos marginais diretos de uma variável $k$ na região $i$ possui influência apenas sobre a variável dependente da região $i$, assim como nos modelos tradicionais. Os impactos indiretos consideram a existência de transbordamentos (LESAGE; PACE, 2009).

$\frac{\partial \mathrm{Y}_{\mathrm{t}}}{\partial \mathrm{X}_{\mathrm{t}}}=\left[\left(I n-\rho W_{\mathrm{ij}}\right)^{-1} \cdot \beta\right]$

Os impactos totais médios são o somatório dos efeitos diretos com os indiretos e eles são calculados pela média dos elementos não nulos da matriz representada pela equação (7). A média dos elementos da diagonal principal da matriz resulta nos impactos diretos, enquanto o somatório das derivadas parciais cruzadas não nulas geram os impactos indiretos médios.

A matriz de ponderação $W$ utilizada neste estudo foi a $k$ vizinhos mais próximo quando $k=15$. O procedimento para selecionar a matriz que melhor reflete o arranjo espacial resultante do fenômeno estudado, sugerido por Stakhovych e Bijmolt (2009), levou em consideração o menor critério de informação das estimações do modelo SAR para seis diferentes matrizes. ${ }^{3}$

A estimação dos modelos espaciais por mínimos quadrados ordinários (MQO) é inconsistente nos modelos de painel espacial, devido à natureza multidimensional da dependência no espaço, denotando simultaneidade da interação. Desse modo, os modelos de painel espacial podem ser estimados por máxima verossimilhança (ELHORST, 2003).

\subsection{Dados}

Os dados usados provêm de várias fontes. No caso de depósitos de patentes, a origem é a Base de Dados Estatísticos de Propriedade Intelectual, versão 1.0, gerada pelo Instituto Nacional de Propriedade Intelectual (Badepi/Inpi), cobrindo o período 2000-2011. São usadas informações de depósitos de patentes de inventores brasileiros com região de residência do inventor. As outras fontes de dados são o sistema AliceWeb, do Ministério do Desenvolvimento, Indústria e Comércio Exterior, a Relação Anual de Informações Sociais (Rais) e o Instituto Brasileiro de Geografia e Estatística (IBGE). O período 2000-2011 é dividido em quatro subperíodos,

3 Os resultados das regressōes SAR para microrregiōes, considerando as matrizes de distância inversa, distância inversão ao quadrado, 5, 10,15 e 20 vizinhos mais próximos, são apresentados na Tabela 1 do Apêndice. 
definidos em função da taxa de crescimento do patenteamento per capita para os triênios 2000-2002, 2003-2005, 2006-2008 e 2009-2011.

Segue-se recomendação da literatura em trabalhar com uma média trienal de patentes para suavizar possíveis variaçôes anuais dos dados. A segunda vantagem dessa abordagem de médias trienais é minimizar o efeito da ocorrência de zeros na variável dependente. Assim, a análise empírica deste trabalho deve ser feita por meio de um painel de dados espaciais, em que cada unidade da cross section é observada em diferentes períodos do tempo.

É importante destacar que serão consideradas apenas as localidades que possuem ao menos uma patente em cada período analisado, dado que é necessário computar a taxa de crescimento do patenteamento interperíodos e o objetivo da análise é verificar a capacidade de catchinp up das regiōes patenteadoras.

Assim, a possível convergência de atividade tecnológica no Brasil é investigada em regiôes que já iniciaram o processo de desenvolvimento tecnológico por possuírem ao menos uma patente. $\mathrm{O}$ procedimento de trabalhar apenas com regiōes patenteadoras também foi utilizado por Acs et al. (1992) e Varga (1998) ${ }^{4}$. As definições e fontes de cada variável são expostas a seguir.

\subsubsection{Variável dependente: taxa de crescimento dos depósitos de patentes per capita (PATpc, proxy da taxa de invenção regional)}

A literatura adota amplamente o conceito de patente para representar o produto da invenção, dadas as principais vantagens dessa proxy, a saber: representa o resultado do processo inventivo que possui aplicabilidade e, principalmente, grau de novidade; e disponibilidade, comparabilidade e riqueza dos dados de patentes, como informações da residência do inventor, classificação da tecnologia, entre outras. ${ }^{5}$

Para se calcular a variável dependente, os dados de depósitos de patentes são somados por região de residência do inventor. No caso de um processo de patente

4 Foi realizado um teste de robustez para confirmar se os principais resultados do artigo se mantêm quando consideradas todas as microrregiôes, eliminando possíveis dúvidas quanto a viés de seleção (Tabela 2, do Apêndice). Para realizar o teste de robustez, foi utilizado um procedimento sugerido por Wooldridge (2010), em que é acrescido um valor baixo (0,000001) para se calcular o logaritmo natural das variáveis que possuem zero. Neste caso, ao se calcular a diferença entre os valores final e inicial dos logaritmos, não se obtêm valores missings da variável dependente (taxa de crescimento do patenteamento per capita).

5 Devem ser consideradas, também, as habituais limitações das patentes como medidas de inovação, como subestimação do processo inventivo, falta de valor econômico de algumas patentes e falta de conexão precisa com o valor econômico da tecnologia (NAGAOKA; MOTOHASHI; GOTO, 2010). Muitos trabalhos, inclusive, utilizam outros indicadores para complementar o estudo da inovação, como gastos em P\&D ou artigos científicos (SIMÔES et al. 2002; SIMÔES et al. 2009). No entanto, não existem medidas perfeitas da atividade inovadora. Logo, as patentes são medidas críveis da atividade inovativa, segundo Acs e Audretsch (1989), e são indicadoras do potencial de inovação regional (CEH, 2001). 
ter mais que um inventor, uma fração proporcional de cada patente é designada a cada região de residência do inventor, como é sugerido nos estudos da literatura da área (MORENO; PACI; USAI, 2005). Em seguida, calcula-se a média trienal da soma anterior e divide-se pela média trienal da população da respectiva região, na escala de patentes por 10 mil habitantes, antes de se aplicar o logaritmo natural. A taxa de crescimento é medida como subtração das patentes per capita em logaritmo dos dois períodos, ou seja:

Taxa de crescimento de $P A T p c_{t}=\ln P A T p c_{t}-\ln P A T p c_{t-1}$

As estatísticas descritivas apresentadas a seguir foram feitas em nível de microrregião, que possui um grau menor de agregação. Espera-se que não existam grandes perdas com essa abordagem, pois as estatísticas de patentes mantêm o mesmo padrão de concentração, independentemente do nível de agregação.

A taxa de crescimento do patenteamento per capita das microrregiões brasileiras possui característica diferente do patenteamento em nível. As Figuras 1 e 2 mostram uma escala de gradação de tons que variam entre as maiores e as menores taxas de crescimento e patenteamento per capita em nível, respectivamente, na média do período 2000-2011.

\section{FIGURA 1}

Taxas de crescimento das patentes por habitantes, segundo microrregiōes brasileiras Média 2000-2011

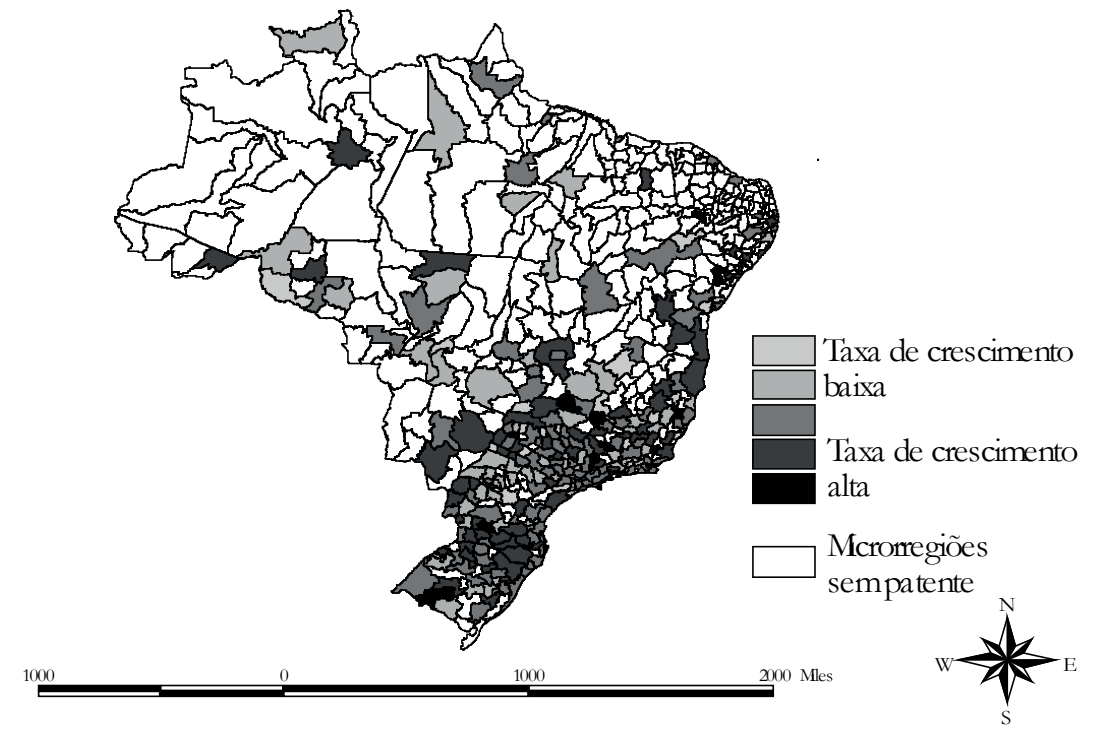

Fonte: Base de Dados Estatísticos de Propriedade Intelectual - Badepi/Inpi, v. 1.0; Instituto Brasileiro de Geografia e Estatística - IBGE. Elaboração do autor a partir do software Arcview 3.2. 
No caso da Figura 1, existem microrregiōes que apresentam maiores taxas de crescimento (vermelho claro) que, embora estejam em sua maioria no Sul e Sudeste, não coincidem com aquelas de maior patenteamento; entre elas estão Bacia de São João (RJ), Patrocínio (MG), Santa Rita do Sapucaí (MG), Palmas (PR), Colatina (ES), Auriflama (SP), Santo Antônio de Pádua (RJ), por exemplo.

\subsubsection{Variáveis explicativas ${ }^{6}$}

Nivel de patentes per capita no periodo inicial (PATpc)

O patenteamento per capita inicial foi inserido no modelo para captar a existência de convergência/divergência tecnológica. A variável é construída a partir dos depósitos de patentes em relação à população da região em análise. A Tabela 1 apresenta as dez microrregióes com mais depositantes de patentes por 10 mil habitantes, na média do período.

TABELA 1

Microrregióes brasileiras com maior patenteamento Média 2000-2011

\begin{tabular}{l|ccc}
\hline Microrregiōes & UF & $\begin{array}{c}\text { Patentes } \\
\text { (por 10 mil habitantes) }\end{array}$ \\
\hline Caxias do Sul & RS & 2,280 \\
Joinville & SC & 1,751 \\
São Carlos & SP & 1,685 \\
Blumenau & SC & 1,389 \\
Marilia & SP & 1,365 \\
Florianópolis & SC & 1,361 \\
São Paulo & SP & 1,240 \\
São Bento do Sul & SC & 1,221 \\
Curitiba & PR & 1,213 \\
Campinas & SP & 1,203 \\
\hline
\end{tabular}

Fonte: Base de Dados Estatísticos de Propriedade Intelectual - Badepi/Inpi, v. 1.0; Instituto Brasileiro de Geografia e Estatística - IBGE. Elaboração dos autores.

A concentração da atividade de patenteamento é uma forte característica do Sistema de Inovação do Brasil. Para o período de 2000 a 2011, a microrregião de São Paulo foi responsável por quase um quarto de todos os depósitos de 6 As estatísticas descritivas das variáveis são apresentadas na Tabela 3 do Apêndice. 
patente do período. Contudo, pode-se observar, no Gráfico 1, que a proporção de patentes para esta área possui uma trajetória descendente, principalmente a partir de 2004.

Se, em 2000, a microrregião de São Paulo respondia por 27\% do patenteamento, em 2010, essa proporção caiu 7 pontos percentuais, passando a ser 20\%, no final da série. Apesar de São Paulo se apresentar como líder isolado em relação ao patenteamento no Brasil, quando se considera dados normalizados pela população, esta região perde a liderança para microrregiốes do Sul, como Caxias do Sul e Joinville. Mas, mesmo assim, tanto São Paulo quanto Campinas se mantêm na lista das dez maiores microrregióes de patenteamento per capita.

\section{GRÁFICO 1}

Participação das principais microrregióes brasileiras no patenteamento total 2000-2011

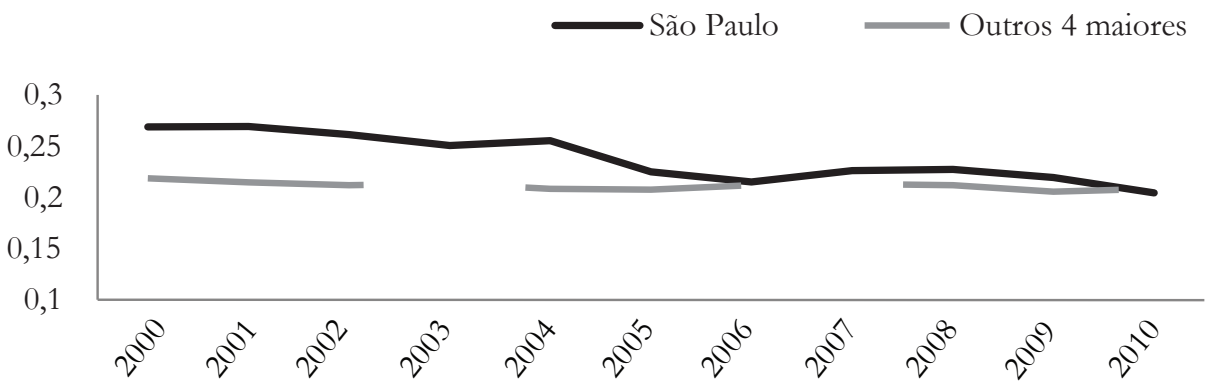

Fonte: Base de Dados Estatísticos de Propriedade Intelectual - Badepi/Inpi v. 1.0; Instituto Brasileiro de Geografia e Estatística - IBGE. Elaboração dos autores.

Nota: As outras quatro maiores microrregiōes são: Rio de Janeiro, Curitiba, Belo Horizonte e Porto Alegre.

A Tabela 1 e a Figura 2 mostram a concentração da atividade inventiva nas microrregiōes brasileiras na Região Centro-Sul do país.

Apesar desse fato, a taxa de crescimento do patenteamento mostra alguma tendência à desconcentração. Contudo, dados descritivos não são suficientes para responder de forma precisa à pergunta deste trabalho. Torna-se necessária, então, a análise de -convergência para confirmar se um movimento de convergência da atividade tecnológica ocorre entre as microrregiōes brasileiras.

Além do nível do patenteamento per capita do período inicial, outras variáveis, representando fatores internos e externos são incluídas na regressão, dado que o estudo avalia a convergência condicional, ou seja, as regiōes convergindo cada uma para seu estado estacionário tecnológico. 
FIGURA 2

Patenteamento por 10 mil habitantes, segundo microrregióes

Média 2000-2011

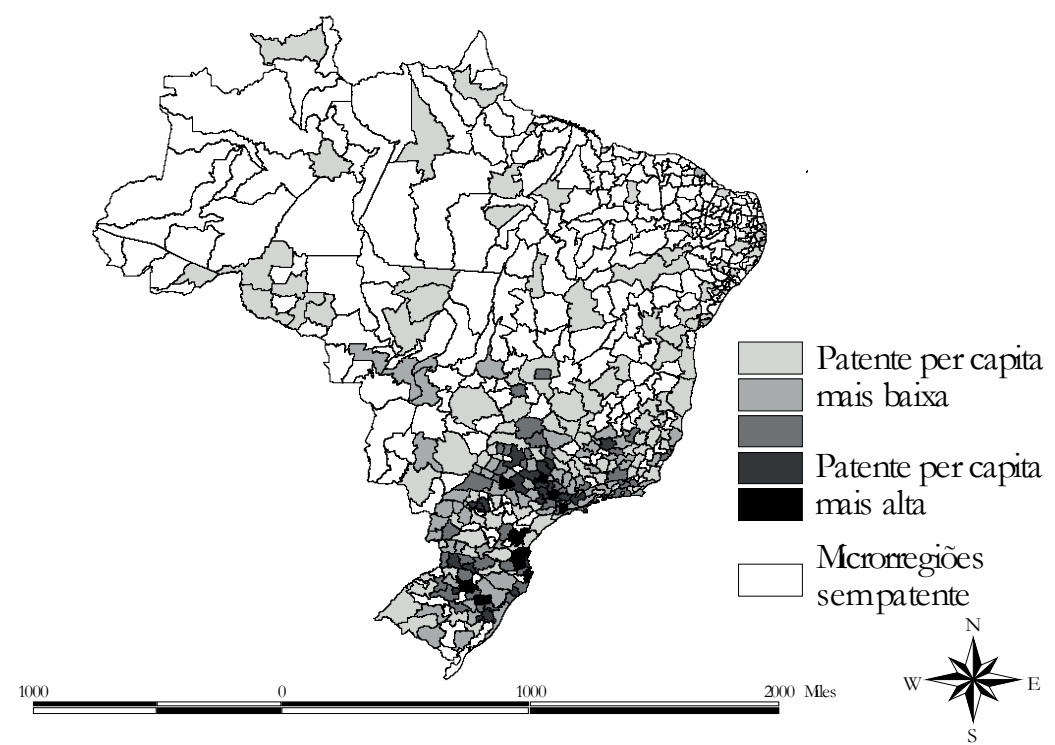

Fonte: Base de Dados Estatísticos de Propriedade Intelectual - Badepi/Inpi v. 1.0; Instituto Brasileiro de Geografia e Estatística - IBGE. Elaboração dos autores a partir do software Arcview 3.2.

Vetor de fatores internos

- CH - escolaridade superior: definida como parcela dos trabalhadores com ensino superior completo. Esta variável tenta capturar a importância da qualificação dos trabalhadores para o desempenho inventivo da região. Carlino et al. (2007) encontraram evidências de que, quanto maior o nível educacional, maior é a capacidade para criar e aplicar novos conhecimentos e, dessa forma, mais acentuada seria a produção tecnológica. A fonte de informações para essa variável é extraída da Relação Anual de Informaçōes Sociais (Rais).

- $P \& D p$ - capacidade de $P \& D$ privado: como dados de $P \& D$ não estão disponíveis no Brasil por microrregióes e para todos os períodos empregados neste estudo, utiliza-se, como proxy da capacidade de $\mathrm{P} \& \mathrm{D}$ industrial, a proporção de profissionais de ocupações selecionadas que têm maior propensão a contribuir para criação de produtos e processos novos ou aperfeiçoados. Araújo, Cavalcante e Alves (2009), seguindo Gusso (2006), propõem a criação dessa variável, chamada "pessoal ocupado técnico-científico" - PoTec. ${ }^{7}$ De acordo com os autores, existe cerca de 90\% de

7 As ocupações definidas por Araújo, Cavalcanti e Alves (2009), segundo a Classificação Brasileira de Ocupaçóes (CBO) de 2002, foram: profissionais da biotecnologia e biomédicos, engenheiros, pesquisadores, profissionais da matemática e de estatística, analistas de sistemas computacionais, físicos, químicos, profissionais do espaço e da atmosfera e arquitetos. 
correlação entre os gastos de P\&D externos e internos e a PoTec, indicando que essa variável é uma proxy adequada para capacidade de P\&D privado.

- DENS - densidade de emprego: esta variável é calculada pela razão entre o número de pessoas ocupadas e a área, em $\mathrm{km}^{2}$, da região. A utilização desse indicador tenta captar a influência da grande concentração espacial de empregados de funções semelhantes e/ou diferentes em uma mesma unidade territorial, a fim de construir uma proxy para as economias de aglomeração. O número de pessoas ocupadas foi coletado da Rais, enquanto a área foi obtida somando-se as áreas dos municípios que compunham a região, constantes no sítio institucional do IBGE.

- EST - números de estabelecimentos, com mais de um empregado, per capita na região: esta variável busca capturar a estrutura competitiva do mercado de trabalho local. Um sinal positivo do coeficiente indica que o mercado mais competitivo produz maior incentivo ao processo inventivo, corroborando a teoria de Porter e também com os resultados encontrados em Jacobs (1969) e Glaeser et al. (1992). Caso contrário, se sua relação for negativa, de acordo com a teoria MAR, a estrutura monopolista tende a proporcionar melhores resultados.

- PIBpc - Produto Interno Bruto per capita de cada regiäo: foi inserido para capturar as condições econômicas de cada região. Espera-se um sinal positivo para esta variável. Autores como Bilbao-Osorio e Rodríguez-Pose (2004) acreditam que as regiôes carregam características econômicas específicas que podem influenciar a capacidade de inovação e seu crescimento. As informações do PIB municipal foram obtidas a partir dos dados do IBGE e, posteriormente, agregadas para os níveis regionais considerados.

- TAM - porte das empresas: esta variável foi incluída para testar se o porte das empresas influencia a capacidade inventiva, sendo a porcentagem do número de grandes empresas, ou seja, com mais de 500 funcionários em cada região, considerando apenas as empresas com pelo menos um vínculo ativo (empregado). Dessa forma, um sinal positivo e significativo implica que uma estrutura regional com predominância de empresas grandes é mais inovadora. Esta variável foi incluída seguindo Acs e Audretsch (1990) e os dados para sua construção foram obtidos da Rais.

Variáveis explicativas: fatores externos

- BK-importação de bens de capital: considera a parcela do PIB regional gasta com a importação de bens de capital. Foram definidos, a priori, os oito principais parceiros comerciais do Brasil (Alemanha, China, Coreia do Sul, EUA, Japão, 
França, Itália e Reino Unido). Em seguida, a partir dos dados da plataforma AliceWeb, do Ministério do Desenvolvimento, Indústria e Comércio Exterior, foi possível selecionar o valor gasto com importações de bens de capital realizadas entre cada região e os principais parceiros brasileiros, supracitados. O objetivo dessa variável é captar a influência do conhecimento tecnológico incorporado em bens de capital no progresso técnico de regióes brasileiras, tendo em vista que o comércio de bens é considerado um importante canal de transmissão de conhecimento tecnológico (COE; HELPMAN, 1995; KELLER, 1998).

- Rho - defasagem espacial da taxa de crescimento de patentes per capita: capta a influência dos vizinhos sobre a taxa de crescimento regional das patentes per capita, com base em um critério de conectividade, representado por uma matriz de ponderação espacial.

\section{Resultados e discussão}

\subsection{Resultados do modelo de convergência de patenteamento microrregional}

Os resultados das regressões em painel para os condicionantes da taxa de crescimento das patentes per capita para as 262 microrregiões com patentes são apresentados na Tabela 2. O método de efeitos fixos é considerado, pelo teste de Hausman, o mais adequado.

Os sinais e significância dos determinantes do crescimento do patenteamento foram muito próximos entre os dois modelos (EF e EF-SAR). No entanto, como foi detectada a presença de dependência entre as unidades de corte transversal, por meio do teste de CD de Pesaran (2007), o processo de convergência ou divergência da atividade tecnológica deve ser investigado levando-se em conta a dependência espacial, para que o estimador não seja inconsistente.

O principal resultado aponta convergência do patenteamento, por meio do coeficiente negativo e significativo da variável patente per capita inicial. Esse fato indica um processo de desconcentração regional da atividade de patenteamento no Brasil, conforme resultados prévios da literatura brasileira e internacional sobre o tema.

Lemos et al. (2006), por exemplo, já indicavam um processo de desconcentração da atividade produtiva. Freitas et al. (2010) encontraram resultado semelhante para os estados brasileiros para o período de 1990 a 2001. Para os Estados Unidos, O'Huallacháin e Leslie (2005) verificaram a existência de convergência tecnológica (catching up tecnológico), embora com taxas baixas e constantes, entre 1963 e 1993. No entanto, de 1993 até 2003, houve um aprofundamento no patenteamento em 
regiōes específicas, o que intensificou o processo de divergência. $\mathrm{Na}$ verdade, as regiôes que patenteavam menos cresceram e se transformaram nas líderes, ou seja, saltaram para frente dos antigos condutores do avanço tecnológico.

TABELA 2

Resultados das regressóes para os condicionantes da taxa de crescimento das patentes per capita em microrregióes brasileiras 2000-2011

\begin{tabular}{|c|c|c|}
\hline \multirow{2}{*}{ Variáveis } & \multicolumn{2}{|c|}{ Microrregióes } \\
\hline & EF & EF-SAR \\
\hline \multirow[t]{2}{*}{ Patentes per capita no período inicial (PATpc) } & $-1,116^{* * *}$ & $-1,114^{* * *}$ \\
\hline & $(0,0446)$ & $(0,036)$ \\
\hline \multirow[t]{2}{*}{ Escolaridade superior $(\mathrm{CH})$} & $-0,231$ & $-0,246$ \\
\hline & $(0,209)$ & $(0,169)$ \\
\hline \multirow[t]{2}{*}{ Capacidade de $P \& D$ privado $(P \& D p)$} & $-0,194^{* *}$ & $-0,192^{* *}$ \\
\hline & $(0,0974)$ & $(0,079)$ \\
\hline \multirow[t]{2}{*}{ Densidade de emprego (DENS) } & $1,290^{* * *}$ & $1,291^{* * *}$ \\
\hline & $(0,422)$ & $(0,341)$ \\
\hline \multirow[t]{2}{*}{ Número de estabelecimentos (EST) } & $1,259^{* *}$ & $1,313^{* * *}$ \\
\hline & $(0,578)$ & $(0,468)$ \\
\hline \multirow[t]{2}{*}{ PIB per capita (PIBpc) } & $-0,494^{* *}$ & $-0,521^{* * *}$ \\
\hline & $(0,205)$ & $(0,166)$ \\
\hline \multirow[t]{2}{*}{ Porte das empresas (TAM) } & $-0,0116$ & $-0,013$ \\
\hline & $(0,0283)$ & $(0,023)$ \\
\hline \multirow[t]{2}{*}{ Importação de bens de capital (pBK) } & 0,0158 & 0,017 \\
\hline & $(0,0142)$ & $(0,011)$ \\
\hline \multirow{2}{*}{$\begin{array}{l}\text { Defasagem espacial da taxa de crescimento } \\
\text { das patentes (Rho) }\end{array}$} & & $-0,145^{*}$ \\
\hline & & $(0,087)$ \\
\hline \multirow[t]{2}{*}{ Constante } & $-2,291^{* *}$ & \\
\hline & $(1,119)$ & \\
\hline \multicolumn{3}{|l|}{ Testes } \\
\hline CD de Pesaran & 3,677 & \\
\hline p-valor & 0,000 & \\
\hline Hausman & 551,63 & \\
\hline p-valor & 0,000 & \\
\hline BIC & & 821,736 \\
\hline AIC & & 775,066 \\
\hline R-quadrado & 0,561 & 0,064 \\
\hline
\end{tabular}

Fonte: Base de Dados Estatísticos de Propriedade Intelectual - Badepi/Inpi v. 1.0; Relação Anual de Informaçôes Sociais Rais; Sistema AliceWeb; Instituto Brasileiro de Geografia e Estatística - IBGE. Elaboração dos autores com base nos resultados do software STATA 13.

Nota: $\mathrm{n}=262, \mathrm{~T}=3, \mathrm{~N}=786$. Erro padrão da estatística entre parênteses. Significância: ${ }^{* *} 0,01 ;{ }^{* *} 0,05 ;{ }^{*} 0,10$. 
Para o Brasil, a evidência de um catching up tecnológico entre 2000 e 2011 mostra que existe tendência de regiôes com menor tradição no tocante à invenção alcançarem as regióes líderes, como São Paulo e Rio de Janeiro. Este resultado suporta a existência de convergência condicional, ou seja, cada região terá diferentes estados estacionários tecnológicos. Isso indica que é importante controlar diferenças estruturais de região para região ao se testar a hipótese de convergência. As variáveis utilizadas neste estudo para tal controle foram divididas em fatores internos e externos.

A segunda coluna da Tabela 2 mostra que o crescimento do patenteamento ocorreu em regiōes mais densas, ou seja, com mais trabalhadores por $\mathrm{km}^{2}$ (DENS). Regiōes maiores propagam com mais facilidade as externalidades, dada a maior facilidade com que ambientes urbanos promovem interações interpessoais e criam maiores oportunidades para os fluxos de informação. O número de estabelecimentos per capita na microrregião (EST) mostra também uma relação positiva e significativa com a variável dependente, indicando que o mercado mais competitivo produz maior incentivo ao processo inovativo, corroborando Jacobs (1969) e Glaeser et al. (1992).

Os coeficientes de PIBpc e P\&Dp também foram significativos, mas apresentaram sinais negativos. A explicação para este resultado pode repousar no próprio fato da convergência do patenteamento. Se as microrregióes que apresentaram maior crescimento do patenteamento foram aquelas que, no período inicial, possuíam um desenvolvimento tecnológico inferior, é possível que a capacidade de P\&D ainda seja baixa, da mesma forma que a renda. Quanto às demais variáveis que controlam características internas da região, capital humano $(\mathrm{CH})$ e tamanho da empresa (TAM), destaca-se que não foram significativas ao nível de 5\% de significância.

$\mathrm{O}$ vetor de características externas obteve evidências fracas de impacto no crescimento do patenteamento per capita. O coeficiente da variável proporção de bens de capital ( $\mathrm{pBK})$, que representa os transbordamentos de conhecimento internacionais, não foi significativo, evidência contrária ao estudo de Ribeiro et al. (2010). Estes autores, contudo, investigavam a convergência de renda e não a de patenteamento per capita.

O coeficiente da defasagem espacial da variável dependente (Rho) é negativo, mas é fracamente significativo (ao nível de 10\%). O coeficiente poderia ser interpretado como indicador de que a taxa de crescimento do patenteamento per capita de uma microrregião está negativamente associada à taxa dos vizinhos, ou seja, existiriam transbordamentos espaciais negativos do crescimento do patenteamento. Entretanto, tal evidência não é robusta porque a significância não se sustenta com o teste de diferentes matrizes de pesos espaciais (Tabela 1 do Apêndice) e com diferentes níveis de agregação regional (Tabela 4). 
Para uma interpretação mais completa do modelo espacial, Le Sage e Pace (2009) sugerem separar os impactos diretos e indiretos, conforme mostra a equação (7). No presente artigo, os resultados desses efeitos são apresentados na Tabela 3 , em que é possível observar que os impactos indiretos sobre o crescimento do patenteamento foram pequenos em relação aos impactos totais, aproximadamente $13 \%$, além de ter significância menor.

TABELA 3

Impactos diretos, indiretos e totais do modelo de convergência de patenteamento para microrregióes brasileiras 2000-2011

\begin{tabular}{|c|c|c|c|}
\hline \multirow[b]{2}{*}{ Variáveis } & \multicolumn{3}{|c|}{ Microrregióes } \\
\hline & $\begin{array}{l}\text { SAR - Impacto } \\
\text { direto }\end{array}$ & $\begin{array}{l}\text { SAR - Impacto } \\
\text { indireto }\end{array}$ & $\begin{array}{c}\text { SAR - Impacto } \\
\text { total }\end{array}$ \\
\hline \multirow{2}{*}{$\begin{array}{l}\text { Patentes per capita no período } \\
\text { inicial (PATpc) }\end{array}$} & $-1,116^{* * *}$ & $0,139^{*}$ & $-0,977^{* * *}$ \\
\hline & $(0,031)$ & $(0,073)$ & $(0,080)$ \\
\hline \multirow[t]{2}{*}{ Escolaridade superior $(\mathrm{CH})$} & $-0,233$ & 0,029 & $-0,204$ \\
\hline & $(0,189)$ & $(0,030)$ & $(0,166)$ \\
\hline \multirow{2}{*}{$\begin{array}{l}\text { Capacidade de } P \& D \text { privado } \\
(P \& D p)\end{array}$} & $-0,188^{* *}$ & 0,024 & $-0,164^{* *}$ \\
\hline & $(0,085)$ & $(0,018)$ & $(0,074)$ \\
\hline \multirow[t]{2}{*}{ Densidade de emprego (DENS) } & $1,284^{* * *}$ & $-0,160^{*}$ & $1,124^{* * *}$ \\
\hline & $(0,329)$ & $(0,094)$ & $(0,300)$ \\
\hline \multirow{2}{*}{$\begin{array}{l}\text { Número de estabelecimentos } \\
\text { (EST) }\end{array}$} & $1,357^{* * *}$ & $-0,171$ & $1,186^{* * *}$ \\
\hline & $(0,443)$ & $(0,109)$ & $(0,388)$ \\
\hline \multirow[t]{2}{*}{ PIB per capita (PIBpc) } & $-0,505^{* * *}$ & 0,064 & $-0,441^{* * *}$ \\
\hline & $(0,165)$ & $(0,040)$ & $(0,146)$ \\
\hline \multirow[t]{2}{*}{ Porte das empresas (TAM) } & $-0,013$ & 0,002 & $-0,011$ \\
\hline & $(0,025)$ & $(0,004)$ & $(0,022)$ \\
\hline \multirow{2}{*}{$\begin{array}{l}\text { Importação de bens de capital } \\
\text { (pBK) }\end{array}$} & 0,016 & $-0,002$ & 0,014 \\
\hline & $(0,012)$ & $(0,002)$ & $(0,010)$ \\
\hline R-quadrado & 0,064 & 0,064 & 0,064 \\
\hline
\end{tabular}

Fonte: Base de Dados Estatísticos de Propriedade Intelectual - Badepi/Inpi v. 1.0; Relação Anual de Informações Sociais Rais; Sistema AliceWeb; Instituto Brasileiro de Geografia e Estatística - IBGE. Elaboração dos autores com base nos resultados do software STATA 13.

Nota: $\mathrm{n}=262, \mathrm{~T}=3, \mathrm{nT}=786$. Erro padrão da estatística entre parênteses. Significância: ${ }^{* * *} 0,01 ;{ }^{* *} 0,05 ;{ }^{*} 0,10$. 
Para os coeficientes da variável patente per capita inicial, especificamente, a direção dos impactos diretos e indiretos é oposta, ou seja, os efeitos indiretos indicam sinal positivo para a relação entre o nível de patente per capita inicial e o crescimento do patenteamento, enquanto os impactos diretos indicam relação negativa. Porém, observando o impacto total, percebe-se que a direção do impacto direto negativo domina o impacto indireto positivo, fazendo com que o efeito resultante total seja negativo, o que indica a existência de convergência de patenteamento.

Ao se considerarem os resultados dos vetores de características internas e externas, não há necessidade de interpretação dos impactos indiretos, dado que estes não foram significativos para quase todas as variáveis e, por isso, os impactos diretos são muito próximos aos impactos totais, que, por sua vez, se assemelham aos coeficientes da Tabela 2.

\subsection{Teste de robustez dos resultados}

Existem na literatura alguns trabalhos que verificaram a sensibilidade dos resultados da convergência de renda ao problema de escala ou de agregação (RESENDE et al., 2016; ALMEIDA; GUIMARÃES, 2014). O problema na utilização de vários níveis de agregação geográfica (escalas espaciais) foi apontado por Arbia (2006), destacando que o resultado de qualquer análise de regressão baseada em dados espaciais depende, essencialmente, do nível de agregação geográfica escolhido e não pode simplesmente ser transferido de um nível de agregação para outro. O problema de escala, ou seja, a sensibilidade dos resultados ao nível de agregação geográfica dos dados faz parte do problema da unidade de área modificável (MAUP). ${ }^{8}$

A questão é saber se esse mesmo problema apontado na convergência de renda existe na convergência de patenteamento. Assim, o objetivo desta subseção é realizar, como teste de robustez, uma análise de sensibilidade dos resultados da convergência de patenteamento entre alguns níveis geográficos mais usados em estudos sobre inovação no Brasil, a saber, microrregião, mesorregião e Regic, no sentido de analisar o sinal dos coeficientes e o nível de significância dessas diferentes unidades espaciais, investigando, assim, se ocorre o problema de escala no processo de convergência de patenteamento.

8 Além do problema de escala, o MAUP é caracterizado pelo problema de zoneamento, ou seja, os dados apresentam diferentes respostas de acordo com a forma de combiná-los em zonas. 
Todos os procedimentos abordados para as microrregiōes na seção anterior também foram realizados para as 110 mesorregiōes brasileiras e para as 116 Regiōes de Influência de Cidades (Regic) que são patenteadoras.

A Tabela 4 apresenta os resultados para efeitos fixos e também para o modelo SAR para as três escalas geográficas analisadas. O principal resultado diz respeito à alta significância da variável patente per capita inicial e ao seu coeficiente negativo para todas as unidades espaciais. Este fato sustenta de forma robusta a existência de um processo de convergência entre as regiōes brasileiras, mesmo com um nível de agregação maior.

TABELA 4

Teste de robustez dos resultados: análise por diferentes escalas territoriais brasileiras 2000-2011

\begin{tabular}{|c|c|c|c|c|c|c|}
\hline \multirow[b]{2}{*}{ Variáveis } & \multicolumn{2}{|c|}{ Microrregióes } & \multicolumn{2}{|c|}{ Mesorregióes } & \multicolumn{2}{|c|}{ Regic } \\
\hline & EF & $\begin{array}{l}\text { EF- } \\
\text { SAR }\end{array}$ & EF & $\begin{array}{l}\text { EF- } \\
\text { SAR }\end{array}$ & EF & $\begin{array}{l}\text { EF- } \\
\text { SAR }\end{array}$ \\
\hline $\begin{array}{l}\text { Patentes per capita no período } \\
\text { inicial (PATpc) }\end{array}$ & $(-)^{* * *}$ & $(-)^{* * *}$ & $(-)^{* * *}$ & $(-)^{* * *}$ & $(-)^{* * *}$ & $(-)^{* * *}$ \\
\hline Escolaridade superior $(\mathrm{CH})$ & $(-)$ & $(-)$ & $(+)$ & $(+)$ & $(-)$ & $(-)$ \\
\hline $\begin{array}{l}\text { Capacidade de } P \& D \text { privado } \\
\text { (P\&Dp) }\end{array}$ & $(-)^{* *}$ & $(-)^{* *}$ & $(+)$ & $(+)$ & $(-)$ & $(-)$ \\
\hline $\begin{array}{l}\text { Densidade de emprego } \\
\text { (DENS) }\end{array}$ & $(+)^{* * *}$ & $(+)^{* * *}$ & $(+)$ & $(+)$ & $(+)$ & $(+)$ \\
\hline $\begin{array}{l}\text { Número de estabelecimentos } \\
\text { (EST) }\end{array}$ & $(+)^{* *}$ & $(+)^{* * *}$ & $(+)$ & $(+)$ & $(+)$ & $(+)^{*}$ \\
\hline PIB per capita (PIBpc) & $(-)^{* *}$ & $(-)^{* * *}$ & $(-)$ & $(-)$ & $(-)$ & $(-)$ \\
\hline Porte das empresas (TAM) & $(-)$ & $(-)$ & $(+)$ & $(+)$ & $(+)$ & $(+)$ \\
\hline $\begin{array}{l}\text { Importação de bens de capital } \\
\text { (pBK) }\end{array}$ & $(+)$ & $(+)$ & $(-)$ & $(-)$ & $(+)$ & $(-)$ \\
\hline $\begin{array}{l}\text { Defasagem espacial da taxa } \\
\text { de crescimento das patentes } \\
\text { (Rho) }\end{array}$ & & $(-)^{*}$ & & $(+)$ & & $(+)$ \\
\hline Testes & & & & & & \\
\hline CD de Pesaran & $(+)^{* * *}$ & & $(+)$ & & $(-)$ & \\
\hline Hausman & $(+)^{* * *}$ & & $(+)^{* * *}$ & & $(+)^{* * *}$ & \\
\hline Número de observações & \multicolumn{2}{|c|}{786} & \multicolumn{2}{|c|}{330} & \multicolumn{2}{|c|}{348} \\
\hline Número de regiões & \multicolumn{2}{|c|}{262} & \multicolumn{2}{|c|}{110} & \multicolumn{2}{|c|}{116} \\
\hline
\end{tabular}

Fonte: Base de Dados Estatísticos de Propriedade Intelectual - Badepi/Inpi v. 1.0; Relação Anual de Informações Sociais - Rais; Sistema AliceWeb; Instituto Brasileiro de Geografia e Estatística - IBGE. Elaboração dos autores com base nos resultados do software STATA 13.

Nota: Os coeficientes foram omitidos devido a uma questão de simplificação.

Significância:*** 0,$01 ;{ }^{* *} 0,05 ;{ }^{*} 0,10$. 
Porém, existe um conjunto de resultados que é sensível à agregação ou escala, em destaque: a autocorrelação espacial. O teste CD de Pesaran indicou a ausência de autocorrelação entre as unidades de cross section para as escalas mais agregadas. Além disso, os coeficientes da defasagem espacial da variável dependente também não foram significativos para mesorregião e Regic.

Desse modo, é possível afirmar que existe uma substancial sensibilidade da dependência espacial em relação à escala geográfica utilizada ao tratar o crescimento da atividade inventiva das regióes brasileiras. Resende et al. (2016) encontraram, com um painel de 1970-2000 sobre o crescimento da renda, que os transbordamentos espaciais eram limitados ao nível de estado, ou seja, não foi observada dependência espacial para este nível de agregação das regiōes brasileiras no estudo da convergência de renda. De forma análoga, sob níveis mais agregados, não se constatam transbordamentos para a taxa de crescimento das patentes. Em nível microrregional existe maior possibilidade de interação entre os agentes econômicos, sendo que o fluxo de conhecimento é maior, assumindo a hipótese de que os fluxos são inversamente relacionados com a distância entre regiōes.

\section{Conclusões}

O principal objetivo deste estudo foi testar a existência de convergência de patenteamento para microrregiōes brasileiras no período de 2000 a 2011 e verificar se o uso de diferentes escalas territoriais influenciava os resultados obtidos. Para testar a robustez dos resultados foi proposto investigar o processo de convergência da atividade de patenteamento para mais duas escalas espaciais: mesorregiōes e Regic.

Os resultados apontam que há um processo de convergência de patenteamento no período referido, o que significa que microrregiōes com menor nível de depósitos de patentes per capita no período inicial apresentaram maiores taxas de crescimento do patenteamento. Esse fato coloca em evidência um processo de desconcentração da atividade inventiva, dado que as microrregióes que mais cresceram no período eram relativamente atrasadas, dando origem a um processo de catching up, em que regiōes menos desenvolvidas voltam seus esforços para recuperar o atraso em relação às regiōes "líderes". Este resultado se mantém para todas as unidades geográficas estudadas.

Em relação à influência espacial sobre o crescimento da atividade inventiva, obtiveram-se evidências muito limitadas. Isso decorre do fato de que o patenteamento em nível das regiōes vizinhas parece possuir influência positiva sobre o crescimen- 
to da atividade inventiva na região, observada por meio dos impactos indiretos. Convém ainda frisar que a evidência de transbordamentos mostrou-se sensível ao problema de escala. Houve uma evidência tênue de transbordamentos no modelo de convergência estimado para microrregiōes, mas que desaparece quando o modelo é estimado para níveis geográficos mais agregados, tais como mesorregião e Regic.

\section{Referências bibliográficas}

ABRAMOVITZ, M. Catching up, forging ahead, and falling behind. The Journal of Economic History, v. 46, n. 2, p. 385-406, 1986.

ACS, Z. J.; AUDRETSCH, D. Innovation and small firms. Cambridge: MIT Press, 1990. . Patents as a measure of innovative activity. Kyklos - International Review for Social Sciences, v. 42, n. 2, p. 171-180, 1989.

ACS, Z. J.; AUDRETSCH, D. B.; FELDMAN, M. P. Real effects of academic research: comment. The American Economic Review, v. 82, n. 1, p. 363-367, 1992.

ALMEIDA, E.; GUIMARĀES, P. M. A análise de convergência de renda no Brasil e o problema de escala espacial. Juiz de Fora: Universidade Federal de Juiz de Fora, 2014. Mimeografado.

ANSELIN, L. Spatial econometrics: methods and models. Boston: Kluwer Academic, 1988.

ARAÚJO, V. C. Dimensão local da inovação no Brasil: determinantes e efeitos de proximidade. 2013. 188 fls. Tese (Doutorado em Engenharia de Produção) - Escola Politécnica, Universidade de São Paulo, São Paulo, 2013.

ARAÚJO, B. C.; CAVALCANTE, L. R.; ALVES, P. Variáveis proxy para os gastos empresariais em inovação com base no pessoal ocupado técnico-científico disponível na Relação Anual de Informaçōes Sociais (RAIS). Radar: Tecnologia, Produção e Comércio Exterior, v. 5, p 16-21, 2009.

ARBIA, G. Spatial econometrics: statistical foundations and applications to regional convergence. Berlin: Springer, 2006.

AZZONI, C. R. Rentabilidade da induistria no interior de São Paulo. São Paulo: Instituto de Pesquisas Econômicas - IPE/USP, 1990. Mimeografado.

BARRO, R. J.; SALA-I-MARTIN, X. Convergence. Journal of Political Economy, v. 100, n. 2, p. 223-251, 1992.

BAUMOL, W. J. Productivity growth, convergence, and welfare: what the long-run data show. The American Economic Review, n. 76, p. 1072-1085, 1986. 
BILBAO-OSORIO, B.; RODRÍGUEZ-POSE, A. From R\&D to innovation and economic growth in the EU. Growth and Change, v. 35, n. 4, p. 434-455, 2004.

CARLINO, G. A.; CHATTERJEE, S.; HUNT, R. M. Urban density and the rate of invention. Journal of Urban Economics, v. 61, n. 3, p. 389-419, 2007.

$\mathrm{CEH}, \mathrm{B}$. Regional innovation potential in the United States: evidence of spatial transformation. Papers in Regional Science, v. 80, n. 3, p. 297-316, 2001.

COE, D.; HELPMAN, E. International R\&D spillovers. European Economic Review, v. 39, n. 5 , p. $859-887,1995$.

DE LONG, J. B. Productivity growth, convergence, and welfare: comment. The American Economic Review, v. 78, n. 5, p. 1138-1154, 1988.

DINIZ, C. C. Desenvolvimento poligonal no Brasil: nem desconcentração nem contínua polarização. Revista Nova Economia, v. 3, n. 1, p. 35-61, 1993.

ELHORST, J. P. Specification and estimation of spatial panel data models. International Regional Sciences Review, v. 26, n. 3, p. 244-268, 2003.

FAGERBERG, J. Technology and international differences in growth rates. Journal of Economic Literature, v. 32, n. 3, p. 1147-1175, 1994.

FELDMAN, M. P. The new economics of innovation, spillovers and agglomeration: a review on empirical studies. Economics of Innovation and Technology, v. 8, p. 5-25, 1999.

FELDMAN, M. P.; FLORIDA, R. The geographic sources of innovation: technological infrastructure and product innovation in the United States. Annals of the Association of American Geographers, v. 84, n. 2, p. 210-229, 1994.

FREITAS, M. V.; GONÇALVES, E.; MONTENEGRO, R. L. G. Desigualdade tecnológica, convergência espacial e transbordamentos: uma análise por estados brasileiros (19902001). Revista Brasileira de Estudos Regionais e Urbanos, v. 4, p. 1-21, 2010.

GLAESER, E. L.; KALLAL, H.; SCHEINKMAN, J.; SHLEIFER, A. Growth in cities. Journal of Political Economy, v. 100, p. 1126-1153, 1992.

GONÇALVES, E. A distribuição espacial da atividade inovadora brasileira: uma análise exploratória. Estudos Econômicos, v. 37, n. 2, p. 405-433, 2007.

GONÇALVES, E.; ALMEIDA, E. S. Innovation and spatial knowledge spillovers: evidence from Brazilian patent data. Regional Studies, v. 43, p. 513-528, 2009.

GRILICHES, Z. The search for R\&D spillovers. Scandinavian Journal of Economics, v. 94, p. 29-47, 1992. 
GUSSO, D. Agentes da inovação: quem os forma, quem os emprega. Tecnologia, exportação e emprego. Brasília: Ipea, 2006. p. 397-444.

IBGE - Instituto Brasileiro de Geografia e Estatística. Divisão Urbano-Regional. Rio de Janeiro, 2013.

JACOBS, J. The economy of cities. Nova York: Random House, 1969.

KELLER, W. Are international R\&D spillovers trade related? Analyzing spillovers among randomly matched trade partners. European Economic Review, v. 42, n. 8, p. 1469-1481, 1998.

KRUGMAN, P. Geography and trade. Cambridge, MA: MIT Press, 1991.

LEMOS, M. B.; MORO, S.; DOMINGUES, E. P.; RUIZ, R. M. A organização territorial da indústria no Brasil. In: NEGRI J. A.; SALERMO M. (Ed.). Inovação, padrões tecnológicos e desempenho das firmas industriais brasileiras. Brasília: Ipea, 2005.

LEMOS, M. B.; CAMPOS, B.; BIAZI, E.; SANTOS, F. Capacitação tecnológica e catching up: o caso das regiōes metropolitanas emergentes brasileiras. Revista de Economia Política, v. 26, n. 1, p. 95-118, 2006.

LeSAGE, J. P.; PACE, R. K. Introduction to spatial econometrics. Boca Raton, Flórida: Chapman and Hall/CRC; Press, Taylor \& Francis Group, 2009.

LUCAS, R. E. On the mechanics of economic development. Econometric Society Monographs, v. 29, p. 61-70, 1988.

MANKIW, N. G.; ROMER, D.; WEIL, D. N. A contribution to the empirics of economic growth. The Quarterly Journal of Economics, v. 107, n. 2. p. 407-437, 1992.

MONTENEGRO, R. L.; GONÇALVES, E.; ALMEIDA, E. Dinâmica espacial e temporal da inovação no estado de São Paulo: uma análise das externalidades de diversificação e especialização. Estudos Econômicos, v. 41, n. 4, p. 743-776, 2011.

MORENO, R.; PACI, R.; USAI, S. Spatial spillovers and innovation activity in European regions. Environment and Planning A, v. 37, p. 1793-1812, 2005.

NAGAOKA, S.; MOTOHASHI, K.; GOTO, A. Patent statistics as an innovation indicator. In: HALL; B. H.; ROSENBERG, N. (Ed.). Handbook of Economics of Innovation. Amsterdam: Elsevier, 2010. cap. 5.

O’HUALLACHÁIN, B.; LESLIE, T. F. Spatial convergence and spillovers in American invention. Annals of the Association of American Geographers, v. 95, n. 4, p. 866-886, 2005.

PESARAN, M. H. A simple panel unit root test in the presence of cross-section dependence. Journal of Applied Econometrics, v. 22, n.2, p. 265-312, 2007. 
RESENDE, G. M.; DE CARVAlHO, A. X. Y.; SAKOWSKI, P. A. M.; CRAVO, T. A. Evaluating multiple spatial dimensions of economic growth in Brazil using spatial panel data models. The Annals of Regional Science, v. 56, n. 1, p. 1-31, 2016.

RIBEIRO, E. C. A.; GONÇALVES, E.; FREGUGLIA, R. S. Transbordamentos de conhecimento e capacidade de absorção: uma análise para os estados brasileiros. Economia, Brasília, v. 14, p. 3-27, 2013.

ROMER, P. Endogenous technological change. Journal of Political Economy, v. 98, p. 71$102,1990$.

SALA-I-MARTIN, X. The classical approach to convergence analysis. Economic Journal, Royal Economic Society, v. 106, n. 437, p. 1019-36, 1996.

SIMÕES, R.; BAESSA, A.; CAMPOLINA, B.; SILVA, L. A distribuição espacial da produção científica e tecnológica brasileira: uma descrição de estatísticas de produção local de patentes e artigos científicos. Revista Brasileira de Inovação, v. 1, n. 2, p. 225-251, 2002.

SIMÕES, R.; OLIVEIRA, A.; GITIRANA, A.; CUNHA, J.; CAMPOS, M.; CRUZ, W. A geografia da inovação: uma metodologia de regionalização das informações de gastos em P\&D no Brasil. Revista Brasileira de Inovação, v. 4, n. 1, p. 157-185, 2009.

SOLOW, R. M. A contribution to the theory of economic growth. Quarterly Journal of Economics, v. 70, p. 65-94, 1956.

STAKHOVYCH, S.; BIJMOLT, T. H. Specification of spatial models: a simulation study on weights matrices. Papers in Regional Science, v. 88, n. 2, p. 389-408, 2009.

USAI, S. The geography of inventive activity in OECD regions. Regional Studies, v. 45, n. 6, p. 711-731, 2011.

VARGA, A. University research and regional innovation: a spatial econometric analysis of academic technology transfers. New York: Springer Science \& Business Media, 1998. v. 13.

WOOLDRIDGE, J. M. Econometric analysis of cross section and panel data. Cambridge, MA: MIT press, 2010. 


\section{Apêndice}

TABELA 1

Tabela para seleção da matriz de pesos espaciais, segundo menor critério de informação (microrregiôes)

\begin{tabular}{|c|c|c|c|c|c|c|}
\hline Variáveis & SAR-wdi & SAR-wdi2 & SAR-k5 & SAR-k10 & SAR-k15 & SAR-k20 \\
\hline \multirow[t]{2}{*}{ PATpc } & $-1,111^{* * *}$ & $-1,113^{* * *}$ & $-1,115^{* * *}$ & $-1,115^{* * *}$ & $-1,114^{* * *}$ & $-1,115^{* * *}$ \\
\hline & $(0,036)$ & $(0,036)$ & $(0,036)$ & $(0,036)$ & $(0,036)$ & $(0,036)$ \\
\hline \multirow[t]{2}{*}{$\mathrm{KH}$} & $-0,247$ & $-0,233$ & $-0,231$ & $-0,230$ & $-0,246$ & $-0,239$ \\
\hline & $(0,169)$ & $(0,169)$ & $(0,169)$ & $(0,169)$ & $(0,169)$ & $(0,170)$ \\
\hline \multirow[t]{2}{*}{ P\&Dp } & $-0,196^{* *}$ & $-0,195^{* *}$ & $-0,194^{* *}$ & $-0,193^{* *}$ & $-0,192^{* *}$ & $-0,195^{* *}$ \\
\hline & $(0,079)$ & $(0,079)$ & $(0,079)$ & $(0,079)$ & $(0,079)$ & $(0,079)$ \\
\hline \multirow[t]{2}{*}{ DENS } & $1,210^{* * *}$ & $1,278^{* * *}$ & $1,291^{* * *}$ & $1,293^{* * *}$ & $1,291^{* * *}$ & $1,288^{* * *}$ \\
\hline & $(0,345)$ & $(0,342)$ & $(0,342)$ & $(0,342)$ & $(0,341)$ & $(0,342)$ \\
\hline \multirow[t]{2}{*}{ EST } & $1,266^{* * *}$ & $1,284^{* * *}$ & $1,261^{* * *}$ & $1,266^{* * *}$ & $1,313^{* * *}$ & $1,288^{* * *}$ \\
\hline & $(0,467)$ & $(0,469)$ & $(0,469)$ & $(0,469)$ & $(0,468)$ & $(0,470)$ \\
\hline \multirow[t]{2}{*}{ PIBpc } & $-0,583^{* * *}$ & $-0,509^{* * *}$ & $-0,496^{* * *}$ & $-0,503^{* * *}$ & $-0,521^{* * *}$ & $-0,506^{* * *}$ \\
\hline & $(0,174)$ & $(0,166)$ & $(0,167)$ & $(0,167)$ & $(0,166)$ & $(0,166)$ \\
\hline \multirow[t]{2}{*}{ TAM } & $-0,011$ & $-0,011$ & $-0,012$ & $-0,012$ & $-0,013$ & $-0,012$ \\
\hline & $(0,023)$ & $(0,023)$ & $(0,023)$ & $(0,023)$ & $(0,023)$ & $(0,023)$ \\
\hline \multirow[t]{2}{*}{ BK } & 0,017 & 0,016 & 0,016 & 0,016 & 0,017 & 0,016 \\
\hline & $(0,012)$ & $(0,012)$ & $(0,012)$ & $(0,012)$ & $(0,012)$ & $(0,012)$ \\
\hline \multirow[t]{2}{*}{ Rho } & $-0,500$ & $-0,087$ & $-0,005$ & $-0,030$ & $-0,145^{*}$ & $-0,075$ \\
\hline & $(0,306)$ & $(0,090)$ & $(0,048)$ & $(0,070)$ & $(0,087)$ & $(0,106)$ \\
\hline Observações & 786 & 786 & 786 & 786 & 786 & 786 \\
\hline $\mathrm{R}$ quadrado & 0,071 & 0,062 & 0,058 & 0,059 & 0,064 & 0,061 \\
\hline AIC & 775,074 & 776,940 & 777,868 & 777,698 & 775,066 & 777,369 \\
\hline $\mathrm{BIC}$ & 821,743 & 823,609 & 824,538 & 824,368 & 821,736 & 824,039 \\
\hline
\end{tabular}

Fonte: Base de Dados Estatísticos de Propriedade Intelectual - Badepi/Inpi v. 1.0; Relação Anual de Informações Sociais - Rais; Sistema AliceWeb; Instituto Brasileiro de Geografia e Estatística - IBGE. Elaboração dos autores com base nos resultados do software STATA 13

Nota: Erro padrão da estimativa em parênteses. Significância: ${ }^{* * *}=0,01 ;{ }^{* *}=0,05 ;{ }^{*}=0,1, \mathrm{n}=262, \mathrm{~T}=3, \mathrm{nT}=786$. wdi $=$ matriz de distância inversa; wdi2 = matriz de distância inversa ao quadrado; k5, k10, k15 e k20 são matrizes que consideram, respectivamente, os $5,10,15$ e 20 vizinhos mais próximos. 
TABELA 2

Resultados das regressóes em painel para os condicionantes da taxa de crescimento das patentes per capita, incluindo todas as microrregióes brasileiras

2000-2011

\begin{tabular}{|c|c|c|c|c|}
\hline \multirow[b]{2}{*}{ Variáveis } & \multicolumn{4}{|c|}{ Microrregiōes } \\
\hline & SAR - média & $\begin{array}{c}\text { SAR - efeito } \\
\text { direto }\end{array}$ & $\begin{array}{l}\text { SAR - efeito } \\
\text { indireto }\end{array}$ & SAR - total \\
\hline \multirow[t]{2}{*}{ PATpc } & $-1,274^{* * *}$ & $-1,275^{* * *}$ & 0,001 & $-1,274^{* * *}$ \\
\hline & $(0,023)$ & $(0,020)$ & $(0,059)$ & $(0,064)$ \\
\hline \multirow[t]{2}{*}{$\mathrm{CH}$} & 0,281 & 0,311 & $-0,002$ & 0,309 \\
\hline & $(0,378)$ & $(0,419)$ & $(0,021)$ & $(0,418)$ \\
\hline \multirow[t]{2}{*}{ P\&Dp } & $-0,054$ & $-0,048$ & 0,001 & $-0,047$ \\
\hline & $(0,110)$ & $(0,119)$ & $(0,006)$ & $(0,118)$ \\
\hline \multirow[t]{2}{*}{ DENS } & 1,083 & 1,054 & $-0,006$ & 1,048 \\
\hline & $(0,975)$ & $(0,943)$ & $(0,062)$ & $(0,934)$ \\
\hline \multirow[t]{2}{*}{ EST } & $2,027^{*}$ & $2,131^{* *}$ & $-0,007$ & $2,124^{* *}$ \\
\hline & $(1,079)$ & $(1,005)$ & $(0,105)$ & $(0,991)$ \\
\hline \multirow[t]{2}{*}{ PIBpc } & $-0,153$ & $-0,102$ & 0,002 & $-0,101$ \\
\hline & $(0,545)$ & $(0,537)$ & $(0,021)$ & $(0,536)$ \\
\hline \multirow[t]{2}{*}{ TAM } & $-0,032$ & $-0,031$ & 0,000 & $-0,031$ \\
\hline & $(0,042)$ & $(0,043)$ & $(0,002)$ & $(0,043)$ \\
\hline \multirow[t]{2}{*}{$\mathrm{pBK}$} & $-0,010$ & $-0,012$ & 0,000 & $-0,011$ \\
\hline & $(0,025)$ & $(0,025)$ & $(0,001)$ & $(0,025)$ \\
\hline \multirow[t]{2}{*}{ Rho } & 0,003 & & & \\
\hline & $(0,050)$ & & & \\
\hline BIC & 7637,421 & & & \\
\hline AIC & 7691,65 & & & \\
\hline R-quadrado & 0,190 & & & \\
\hline
\end{tabular}

Fonte: Base de Dados Estatísticos de Propriedade Intelectual - Badepi/Inpi v. 1.0; Relação Anual de Informações Sociais -

Rais; Sistema AliceWeb; Instituto Brasileiro de Geografia e Estatística - IBGE. Elaboração dos autores com base nos resultados do software STATA 13.

Nota: Erro padrāo da estatística entre parênteses. Significância:*** 0,$01 ;{ }^{* *} 0,05 ;{ }^{*} 0,10$. 
TABELA 3

Estatísticas descritivas das variáveis (microrregióes) 2000-2011

\begin{tabular}{lcccccc}
\hline Variáveis & Observaçóes & Média & $\begin{array}{c}\text { Desvio } \\
\text { padrão }\end{array}$ & Mínimo & Máximo \\
\hline Tx_CrescPATpc & 786 & 0,013 & 0,654 & $-2,321$ & 2,624 \\
PATpc & 786 & 0,312 & 0,348 & 0,002 & 2,369 \\
CH & 786 & 0,096 & 0,036 & 0,028 & 0,314 \\
P\&Dp & 786 & 0,004 & 0,003 & 0,000 & 0,032 \\
DENS & 786 & 65,014 & 232,433 & 0,392 & 3645,535 \\
EST & 786 & 0,065 & 0,021 & 0,020 & 0,156 \\
PIBpc & 786 & 14,421 & 8,568 & 1,871 & 62,203 \\
TAM & 786 & 3,336 & 3,049 & 0,000 & 20,320 \\
pBK & 786 & 3,264 & 7,197 & 0,000 & 84,238 \\
\hline
\end{tabular}

Fonte: Base de Dados Estatísticos de Propriedade Intelectual - Badepi/Inpi v. 1.0; Relação Anual de Informaçôes Sociais - Rais; Instituto Brasileiro de Geografia e Estatística - IBGE. Elaboração dos autores a partir do software STATA 13.. 